Uşak Üniversitesi Sosyal Bilimler Dergisi

$2015,8 / 4$

\title{
Ekran Okuryazarlığının Gelişimi ve Geleceğine Yönelik Tahminler
}

\author{
Erol DURAN* \\ İncinur DOLAYLAR ÖZKUL*
}

\section{Öz}

Hayatın her alanında karşımıza çıan ekranlar, okuma yazma ortamı açısından da değişikliğe sebep olmuştur. Küçük yaşlardan itibaren alışılan kâğıt üzerinden okuma ve kâğıda yazma, yerini ekrandan okuma yazmaya bırakmıştır. Bu çalışma ile hızla gelişen ve değişen teknoloji içerisinde ortaya çıan ve gelecekte de büyük bir gelişimle varlığını sürdürecek olan ekran okuryazarlığının gelişim sürecini açıklamak ve geleceğine ilişkin tahminler sunmak amaçlanmaktadır. Çalışmada, ilgili literatür tarayarak toplanan veriler içerik analizi tekniğiyle analiz edilmiştir. Veriler, bilişim teknolojisi şirketlerinin gelecekte bilgisayar, cep telefonu, reklam panosu ve saat ekranının nasıl gelişeceği ve hayatımızı nasıl kolaylaştıracağı ile ilgili videolar izlenerek elde edilmiştir. Videolara internetten erişim sağlanmıştır. Araştırmacılar tarafından bu belgelerden çıkarımlar yapılmıştır. Ayrıca araştırmacılar ekran okuryazarlığının geleceğine yönelik kendi tahminlerini de belirtmişlerdir. Elde edilen bulgulara göre, lider bilişim teknolojisi firmalarının hepsi, gelecekte ekranların yaşamın her noktasında olacağını açıklamaya çalışmaktadırlar. $\mathrm{Bu}$ da genelde bireylerin özelde ise öğretmen ve öğrencilerin ekran okuryazarlığı becerilerinin gelişmek zorunda olduğunun en önemli göstergesidir. $\mathrm{Bu}$ sebeple öğretmenlerimiz ve öğrencilerimiz ekran okuryazarlığını geliştirerek yollarına devam etmelidirler. Gelecekteki bilgi teknolojilerine ayak uyduramayan eğitimcilerin başarılı olmaları imkânsızlaşacaktır.

Anahtar Kelimeler: Okuryazarlık, Ekran, Tahmin.

\section{The Development of Screen Literacy and Predictions for the Future}

\section{Abstract}

The screens, encountered in all areas of our lives, has led to changes interms of reading environment. From an early age accustomed to reading on paper an wrting to screen, was replaced by reading from screen and

* Doç. Dr., Uşak Üniversitesi, Eğitim Fakültesi

** Öğretmen, Milli Eğitim Bakanlığı 
wrting to screen. This study aims to explain the development of the screen, which will continue to exist with a major development in emerging and changing technology in the future and are intended to provide estimates of the future. In this study, the data collected by scanning the literature were analyzed by content analysis. Data were obtained from information technology company, explained how to develop and how to make our lives easier of computer, mobile phone, of billboards and videos. Videos are provided access to the Internet. Researchers are made by inferences from those documents. In addition, the researchers reported in their forecasts for the future of screen literacy. According to the findings, all of the leading IT companies, they try to explain every aspect of life in the future will be in the display. This is generally the biggest indication that private individual shave to thrive if teachers and students display their screen literacy skills. Therefore, our teachers and our students must continue developing ways to screen literacy. Educators can not keep up with the future of information technology will be impossible to be successful.

Keywords: Literacy, Screen, Estimate.

\section{Giriş}

İçinde yaşadığımız çağda her geçen gün artan teknolojik cihaz kullanımı genç kuşak için hem işlevsel, hem eğlenceli, hem de bilgi vericidir. $\mathrm{Bu}$ çağın getirdiği teknoloji eğitim öğretimin de vazgeçilmez bir parçası olmuştur. Buna bağlı olarak bilgisayar kullanımının artması ve uygulama alanlarının daha da yaygınlaştırılması düşüncesi bilgisayarın eğitim sistemine dâhil olmasını sağlamıştır (Çetin vd., 2004: 145). Teknolojinin eğitimin bir parçası hâline gelmesi ve teknolojiyle iç içe olma zorunluluğu ekran okuryazarlığını ortaya çıkarmıştır. Bu çalışma ile ekran okuryazarlığının geçmişten günümüze kadar geçen sürecine 1şık tutulacak ve gelecekte ne kadar ilerleyebileceği açıklanmaya çalışılacaktır.

"Geleneksel olarak okuma-yazmadan bahsettiğimizde, harflerin üzerine yazılı olduğu bir materyale (metin), bu materyal üzerine harfleri işleyecek (yazar) ve bu harfleri çözümleyecek birine (okur) ihtiyaç vardır. Dolayısıyla genel olarak okuma-yazma eylemini okur, metin ve yazar üçgeni içerisinde gerçekleşen bir süreç olarak algılamak mümkündür." (Kurudayığlu ve Tüzel, 2010: 284). Okuryazar ve okuryazar olma durumu gündelik dilde çeşitli biçimlerde karşımıza çıkmaktadır. "Okuryazar, okuması yazması olan, öğrenim görmüş (kimse); okuryazarlık, okuryazar 
olma durumu" anlamina gelmektedir (http://www.tdk.gov.tr, 24/04/2015 tarihinde indirilmiștir).

Khan ve Raza (2012: 15)'ya göre "bilgisayar ve internet kullanımı günden güne artmakta, bilgisayar sistemlerinden okuma yaygınlaşmaktadır." Her alana giren internet, bilgisayar ve akıllı telefonlar eğitim alanına da girmiş ve ekranların insan yaşamında etkin bir şekilde kullanılması ekrandan okumayı ortaya çıkarmıştır. Schoeller (2005), ekrandan okumayı bilgisayarın araç olarak kullanıldığı bir ortamdaki okuma olarak tanımlamaktadır. Başka bir tanıma göre, ekrandan okuma, elektronik metinlerden yapılan okumadır (Ertem ve Özen, 2014: 325). Hull vd. (2003: 10) de dijital okuryazarlığı elektronik biçimde sunulan bilgiyi iletme, değerlendirme ve özümseme yeteneği olarak belirtmiştir.

\section{Ekran Okuryazarlığının Gelişim Süreci}

İnsanoğlu gelecekte de varlığını sürdürecek olan ekranlarla ilk kez televizyonla karşılaşmıştır. Televizyon 1923 yılında, John Logie Baird tarafından üretildiğinde belki de yaşamın odak noktalarından biri hâline geleceği düşünülmemiştir. İlk televizyon görüntüsü ise yine Baird tarafından 1926 yılında yayınlanmıştır. Başlangıçta noktalar hâlinde ve titrek olan görüntülerin kalitesi yine Baird tarafından geliştirilmiştir. 1950'lerde ABD'de ilk renkli televizyon satışa çımıştır (http://tr.wikipedia.org/wiki/Televizyon, 28/05/2015 tarihinde indirilmiştir.). Yıllarca CRT (katot 1şınlı tüp) ekranlı televizyonlar kullanıldıktan sonra yerini daha ince olan plazma televizyonlar, LCD ekranlar ve son olarak LED TV'ler almıştır. Elbette bu süreçte ekrandaki görüntüler gerçeğe daha yakın, renkler ve yazılar ise daha net hâle gelmiştir. Ayrıca 3D teknolojisi ve HD ekranlar da görüntünün kalitesini artırmıştır.

1939 yılında Dr. John V. Atanasoff ve asistanı Clifford Berry ilk elektronik dijital bilgisayarı oluşturduğunda şüphesiz ekran okuryazarlığı kimsenin aklında yoktu. $1945^{\prime}$ de $167 \mathrm{~m}^{2}$ lik bir alanı işgal eden ENIAC (Electronic Numerical Integratorand Automatic Calculator) isimli makine üretildi. ENIAC, 30 ton ağırlığında olup, çalışma hızı 100 hertz idi(Kaya vd., 2005: 4). Şimdiki bilgisayarlardan çok farklıydı fakat gelecek bilgisayarlara temel oluşturdu. 1971 yılında İntel firması 4004 isimli ilk mikro işlemciyi üretti (Pala, 2008: 11). 1985'de ilk portatif DOS bilgisayarı üretildi. Böylece dizüstü bilgisayarlar için ilk ilerleme kayıtlara geçmiş oldu. Sonraları bilgisayarlarla birlikte ekranlar da gelişti, küçüldü ve inceldi. "İlk üretildiğinde bir oda büyüklügünde ve 30 ton ağırlığında olan bilgisayarlar 2000'li yıllarla birlikte mobil yaşama uygun hâle gelerek taşınabilir boyutlara geldi." (İspir vd., 2013: 4). 
Günümüzde bilgisayar ekranları tıpkı televizyonlar gibi incelerek görüntüler daha net hâle gelmiş, ekran parlaklığ̣ düzenlenmiştir. Böylece bilgisayar kullanıcıları için ekrandan okuma yapmak daha kolay bir durum olmuştur.

Ekranlarla karşılaşılan diğer cihaz da cep telefonlarıdır. Martin Cooper 1973'te ilk cep telefonunu geliştirdi. 1989 yılında LED ekranlı telefon satışa sunuldu ve 1993 yılında IBM ilk dokunmatik ekranlı akıllı telefon üretti. 1997 yılında, dünyanın ilk renkli ekranlı telefonu tanıtıldı. Ekran kalitesi çok iyi değildi fakat değişik renklerde menüye sahip olması dikkat çekiciydi. 1999 yılında internete bağlanabilen ilk telefon, 2000 yılında da ilk kameralı telefon üretildi. O dönemdeki ekranlar fazla gelişmemiş (0.1 MP çözünürlüğünde) olduğu için çekilen fotoğrafları telefon ekranından seçmek kolay değildi.

Gelişmeler sayesinde cep telefonlarının yazıll, sözlü ve görsel iletişim sağlaması, bu araçları yaşamımızdaki en önemli unsurlardan biri hâline getirmiştir. Günümüzde telefon ekranlarındaki yüksek çözünürlük, net görüntü, internet bağlantısı ve ekranlar arasındaki hızlı geçişler cep telefonlarının birer bilgisayar gibi kullanılmasını sağlayan gelişmelerden bazılarıdır. Bundan dolayı birçok bireyin hayatındaki işlerin önemli bir kısmı cep telefonu ekranıyla takip edilmektedir. Böylece günün değişik saatlerinde farkında olunmasa da ekrandan okuma yapılmaktadır.

Bilişim teknolojileri her geçen gün gelişirken ekran okuryazarlığı için en büyük adım şüphesiz 1971 yılında "Gutenberg Projesi" ile atıldı. Michael S. Hart tarafından Illinois Üniversitesi'nde başlatılan Gutenberg Projesi'nin amacı 10000 kitaplı elektronik bir halk kütüphanesi oluşturmaktı. 1987 yılında bilgisayar oyunları üreten Eastgate Systems adlı bir firma Michael Joyce'un "Afternoon" adlı kitabını diskette yayınladı. 1990 yılında Serendipity Systems, "PC-Book" adlı e-kitap görüntüleme programını geliştirdi. 1992 yılında e-kitaplar metin tabanlı DOS ortamından grafik tabanlı Windows ortamındaki edisyonlara dönüştürüldü. 1993 yılında Biblio Bytes, internet üzerinden e - kitap satmak üzere ilk web sitesini kurdu. 1994 yılında e - kitap formatının metinden HTML'ye geçişi gerçekleşti ve aynı yıl The Fiction Works isimli e - kitap yayıncı şirketi kuruldu (Ebooktimeline, 2002, 26/04/2015 tarihinde indirilmiştir). Google da, Google Kitapları ile lisans bakımından sorun teşkil etmeyen kitapların hepsini 2002 yılında yayınladı (Aydoğan, 2014: 25). Böylece e-kitaplardaki yeniliklerin sonucunda ekran okuryazarlığı hızla gelişti. Bu gelişimle, e-kitap okuyucular tanınmamış yazarların eserlerini tanıtma imkânı sağlamaktadır. 
Ayrıca yazarların okuyucularından geribildirim almasına da olanak tanımaktadır. (Hawkins, 2000: 17; Day, 2001: 83).

Her alanda karşılaşılan ekranlar okuma ortamı açısından da değişikliğe sebep olmuştur. Küçük yaşlardan itibaren alışılan kâğıt üzerinden okuma, yerini elektronik ekrandan okumaya; dükkânların ve trafik ışıklarının metal üzerindeki tabelalarını okuma ise yerini 1şıklı led tabelalara bırakmaya başlamıştır. Kısacası okuma becerisi kitap, defter vb. gibi yazılı materyallerin dışında bilgisayar, cep telefonu, tepegöz, sunu, reklam panoları vb. elektronik materyaller için de kullanılır hâle gelmiştir (Maden, 2012: 2).

Teknolojinin gelişim sürecinde bilgisayar ekranları da giderek incelmiş, küçülmüş ve görüntü kaliteleri de artmıştır. Laptoplar, tabletler, cep telefonları, e-kitap okuyucular bilgisayarların geliştirilerek çeşitli işlevlerde kullanılan hâlleridir. Önceleri "uzun süreli okuma yapıldığında ekitap okuyucularının bazılarında göz yorgunluğu ortaya çıkmaktadır." (Herring, 2001: 47). Daha sonra bu dezavantajı ortadan kaldırmak ve okuyuculara iyi bir okuma ortamı sunmak için bu cihazların ekranları geliştirilmiştir. Bu konuda atılan en önemli adımlardan biri de "Electrophoretic Ink (Elektroforetik Mürekkep)"in kısaltılmış hali olan e-ink teknolojisidir. E-ink, 1997'de Massachusetts Teknoloji Enstitüsü tarafından başlatılan araştırmalarda geliştirilen, "elektronik kâğıt" ismiyle de anılan bir ekran teknolojisidir (http://tr.wikipedia.org/wiki/Elektronik_M, 18/05/2015 tarihinde indirilmiştir.). E-ink ekranların en temel özelliği gözü yormamasıdır. E-ink ekranlar okuma sırasında basılı (gerçek) bir kitabı okuyormuş hissi verir. Bu sebeple görüntü doğaldır.

Basılı kitaptakine benzer bir his uyandıran bir diğer önemli adım ise geçmişte okuyucuya not alma, altını çizme gibi imkânlar tanımayan ekranların artık bu özelliklere sahip olmasıdır. Bugün gelişen teknoloji ile ortaya çıan tabletler, e-kitap okuyucular ve akıllı telefonlar ile not alma, altını çizme, ayraç ekleme, sayfa çevirme gibi fonksiyonlar sayesinde basılı kitaba benzer özellikler oluşturulmuştur. Ayrıca gelişen ekranlar arka plân rengi, yazı boyutu ve fontunu değiştirebilme, ekran ışığını ayarlama gibi birçok kullanım olanaklarına da sahiptir (Aydoğan, 2014: 30). Bu sayede gerçek kitaba alışmış olan okuyucuya daha çok kolaylık sağlanmıştır. Bunlara ek olarak kolay depolama, geri getirme ve kaynakları kaydetme gibi avantajlarından dolayı elektronik metinler daha çok tercih edilecektir (Dillon, 1992).

Bugün eğitimde de ekranlar etkin bir şekilde kullanılmakta ve ekran okuryazarlığının faydaları araştırılmaktadır. Sınıflarda önceleri tepegöz kullanılırken; şimdilerde hemen her sinıfta projeksiyon cihazları sayesinde 
bilgisayar ekranları, perdeye yansımaktadır. Uzaktan eğitimde de, öğrenci okul ortaminda bulunmasa da bilgiler ekranlar vasitasiyla aktarllabilmektedir.

Eğitimde ekranların kullanılması üzerinde çalışan araştırmacılardan bazıları da ekran okuryazarlığını desteklemektedir. Rockinson-Szapkiw vd. (2012: 265)'e göre, e-ders kitaplarını kullanan öğrencilerin duyuşsal ve psikomotor öğrenmeleri daha yüksek düzeydedir. Grace (2011 s.46) araştırmasında öğrencilerin elektronik kitaplar sayesinde teknoloji cihazlarını kullanmada deneyim kazandığını belirtmektedir. Sayer (2007: 82) ise elektronik yayınların çocuklara sundukları etkileşimli ortamla onların daha üretken olmasına katkıda bulunduğunu savunmuştur. Grimshaw (2007: 598) çalışmasında elektronik kitapların çocukların hikâye kitaplarından aldıkları keyfi ve anlamalarını artırdığını vurgulamıştır. Greenlee-Moore ve Smith (1996: 56) bir metnin anlatımı uzun ve zor olduğunda ekrandan okuyan çocukların okuma isteklerinin daha fazla olduğunu belirtmiştir. Hatta Leu (2006: 3)'ya göre, dünya nüfusunun altıda biri, bilgisayar ekranından okuma yapmaktadır. Şu ana kadar eğitimde bu denli kullanılan ekran teknolojileri, gelecekte daha fazla yaygınlaşacak; bunun bir sonucu olarak bireylerin ekran okuryazarlığı becerileri gelişmiş olacaktır.

\section{Ekranın Teknolojik Açıdan Değerlendirilmesi}

Ekran; bilgisayar, televizyon, cep telefonu, e-kitap okuyucu gibi cihazların görüntülerini sergileyen teknolojik aygıttır. "Ekran, plastik bir muhafaza içinde gerekli elektronik devreleri, güç transformatörünü ve resmi oluşturan birimleri içerir. Ekranla bilgisayar arasındaki iletişimi ekran kartı sağlar." (http://mebk12.meb.gov.tr, 26/05/2015 tarihinde indirilmiştir.). Ekranların ebatları inç ölçü cinsiyle ile ifade edilir. "İnç, ekranların köşegen uzunluklarıdır ve 1 inç yaklaşık 2, 54 cm'ye karşılık gelir." (Kaya vd., 2005: 25).

İnsanlar bilgisayarda ilk olarak CRT (Cathode Ray Tube (Katot Işın Tüpü)) monitörler ile karşılamışlardır. "Televizyon ekranına benzeyen ve içinde katot ışınlı tüp denilen katot tabancaları bulunmaktadır. Katot tabancaları ile ekranın ön tarafında fosfor noktacığı elektron bombardımanına tutulur ve görüntü oluşur." (Hamzaçebi ve Çetiner, 2007: 19). Bu ekranların bazılarında gözü yoran titreşimler olabilmektedir.

Sonraları daha modern olan LCD (Liquid Cyristal Diode) ekranlı cihazlar üretilmeye başlanmıştır. LCD ekranlarda görüntü sıvı kristal diyotlar yardımıyla sağlanmaktadır. Bu diyotlara gerilim uygulandığında, 
içlerindeki moleküllerin polarizasyonu değişmekte ve beraberinde de diyotun geçirgenliği değişmektedir. $\mathrm{Bu}$ duruma dijital saatlerde de rastlanmaktadır. Normalde şeffaf olan bu diyotlara gerilim uygulandığında geçirgenliklerini kaybederler ve siyaha dönerler. Renkli LCD monitörlerde ise çok ufak ve birden fazla diyot kamanı kullanılarak görüntü alınmaktadır." (Özçatalbaş vd., 2008: 65).

Teknoloji denilince akla hep ilerleme ve gelişme beklentisi gelmektedir. Dokunmatik ekranlar da bu beklentileri karşılayan gelişmelerden biridir. Günümüzde kullanılan birçok cihazda tuşlar yerine artık dokunmatik ekranlar bulunmaktadır. "Dokunmatik teknolojisi, elektronik cihazların parmak veya özel kalemler vasıtasıyla hafifçe dokunarak kumanda edilmesine imkân verir. Dokunmatik cihazlarda günümüzde kullanılan üç temel teknoloji mevcuttur: Dirençli (Rezistif) Teknoloji, Yüzey Dalgası (SurfaceWave) Teknolojisi ve Kızılötesi (Infrared) teknolojisidir." (http://tr.wikipedia.org/wiki/Dokunmatik, 25/05/2015 tarihinde indirilmiştir.). Bugün teknoloji mağazalarına gidildiğinde çoğu cihazın dokunmatik ekranlı olduğu görülmektedir. Yakın gelecekte de dokunmatik ekranların bütün cihazlarda kullanılacağını söyleyebiliriz.

Dokunmatik ekranlardan başka bir diğer teknolojik gelişme de 3D teknolojisidir. 3D ekranda görüntünün derinliğinin, genişliğinin ve yüksekliğinin olmasıdır. Günümüzde ekrandaki nesneleri her açıdan görmeyi sağlayan 3D teknolojisi izleyiciye ekranda görülen alanda bulunuyormuş hissi vermektedir. Ayrıca bugünlerde neredeyse tüm televizyonlar için kullanılan HD ekranlar, yüksek görüntü netliğini vurgulamaktadir.

Gerek net görüntü oluşturmak, gerek taşınabilirliği sağlamak, gerekse hayatımızı kolaylaştırmak için bu ekran çeşitleri üretilmiştir. Günümüzde ekranların net görüntüsünün yanında göz sağlığını da korumak için e-ink teknolojisi geliştirilmiştir.

\section{Araştırmanın Amacı ve Önemi}

Çalışmanın amacı, hızla gelişen ve değişen teknoloji içinde ortaya çıkan ve gelecekte de büyük bir gelişimle varlığını sürdürecek olan ekran okuryazarlığının gelişim sürecini açılamak ve geleceğine ilişkin tahminler sunmaktır.

Araştırmada ilgili literatürün taraması yapıldığında ekran okuryazarlığının dünü, bugünü ve yarını hakkında yeterli sayıda çalışma yapılmadığı görülmektedir. Hızla gelişen teknolojinin karşısında öğrenci ve öğretmenlerin ekran okuryazarlığ hakkında yeterli düzeyde bilgilenmeleri gerekmektedir. Bu araştırma, hızla gelişen teknolojinin karşısında öğrenci 
ve öğretmenleri ekran okuryazarlığının dünü, bugünü ve geleceği hakkında bilgilendirmesi yönünden önemlidir.

\section{Araştırmanın Yöntemi}

Araştırmada betimsel tarama modeli kullanılmıştır. Çalışmada, literatür tarayarak toplanan veriler içerik analizi tekniğiyle analiz edilmiştir. İçerik analizi, belirli kurallara dayalı kodlamalarla kitap, kitap bölümü, mektup, tarihsel dokümanlar, gazete başlıkları ve yazıları gibi bir metnin bazı sözcüklerinin daha küçük içerik kategorileri ile özetlendiği sistematik, yinelenebilir bir tekniktir (Sert vd., 2012: 2). "İçerik analizi, insan davranışlarını ve doğasını belirleme üzerinde doğrudan olmayan yollarla çalışma imkânı tanır. Yapılacak çalışma, metin veya metinlerden oluşan bir kümenin içindeki belli kelimelerin veya kavramların varlığını belirlemeye yönelik yapılır." (Büyüköztürk vd., 2014: 240).

\section{Veri Toplama Süreci}

Veriler Microsoft, Intel, Samsung ve IBM şirketlerinin gelecekte bilgisayar, cep telefonu, reklam panosu ve saat ekranının nasıl gelişeceği ve hayatımızı nasıl kolaylaştıracağı ile ilgili videoları izlenerek elde edilmiştir. Videolara internetten erişim sağlanmıştır. Microsoft, Intel ve Samsung'a ait ikişer video $6 \mathrm{kez}$ izlenip incelenmiştir. Ayrıca, IBM'in gelecekteki bilgisayarlarla ilgili tahminleri de incelenmiştir. Araştırmacılar tarafından bu belgelerden çıkarımlar yapılmıştır. Bunun yanısıra araştırmacılar ekran okuryazarlığının geleceğine yönelik kendi tahminlerini de belirtmişlerdir.

\section{Geçerlik}

Araştırmada geçerliliği sağlamak için, videolar ve haberler üç alan uzmanı tarafından incelenmiştir. Alınan uzman görüşleri doğrultusunda, lider bilişim teknolojisi şirketlerinin ekranların geleceğine yönelik tahminlerini içeren çıarımlar yapılmıştır.

\section{Bulgular ve Yorum}

Intel gelecekte kol saati ile bilgisayar ekranlarının taşınacağını, insanların bilgisayar ekranlarını konuşarak kontrol edebileceğini, cep telefonları, kol saatleri ve bilgisayarların birbirine paralel olarak çalışacağını tahmin etmektedir. Bunun yanında otomobillerin kapılarının ve bagajının cep telefonu ekranı ile açılacağını, arabada dinlenecek müziklerin telefon ekranına verilen konuşma komutları ile dinleneceğini, yine ekrandan konuşma komutları ile yol tarifi alınabileceğini vurgulamaktadır. Ayrıca 
insanların müzikli eğlence merkezlerinde bileklerinde taşıyacakları bileklik ve kulaklarındaki küçük cihazlar sayesinde hep birlikte aynı müzikte dans edilebilecekleri, hatta müziklerin cep telefonu ekranıla seçebileceği düşünülmektedir. Eğlence merkezindeki herkes aynı müzikle dans ederken, dışarıdaki insanların, müzik sesini eğlence merkezindeki kişilerin kulaklık kullanmaları sayesinde duymayacağı ve bu nedenle hiç kimsenin rahatsız olmayacağ 1 belirtilmiştir (https://www.youtube.com/watch?v=g_cauM3kccI, 30/05/2015 tarihinde indirilmiştir.).

Intel'in bir başka videosuna göre gelecek teknolojisi sayesinde her şey daha hızlı yapabilecektir. Bilgisayarların yüz tanıma girişinin olacağı, ses asistanı ile bilgisayar başında yazarak değil konuşarak bilgisayardaki iş ve işlemlerin yapılabileceği, bellek yardımı olmadan bir ekrandan başka bir ekrana kablosuz bilgi aktarılabileceği tahminler arasındadır. Bunun sonucunda gelecekte bağlantı veya şarj kabloları da kalmayacaktır. Telefonlar, bluetooth kulaklıklar arabada veya evde küçük panellerin içine konularak kablosuz bir şekilde şarj edilebilecektir. Ayrıca kitaplardaki bilgilerin bilgisayar ekranına tutularak, ekran içine kaydedileceği ve hareketli resimlerin olacağı düşünülmektedir. Bu sayede kitaplar başta çocuklar olmak üzere herkesin ilgisini çekerek okunacaktır (https://www.youtube.com/watch?v=9Tw-f3i-08k, 30/05/2015 tarihinde indirilmiştir.).

Samsung'a göre gelecekte telefonlar incecik OLED ekranlar olacaktır. OLED'ler plastik ve kıvrılabilir malzeme üzerinde olabildiğinden, telefonlar istenildiğinde kol saatine; istenildiğinde tabletlere dönüşebilecektir (https://www.youtube.com/watch?v=-2faggNVQtM, 31/05/2015 tarihinde indirilmiştir.). Yine Samsung gelecekte katlanabilir, bükülebilir, kırılmaz ekranlar olacağını; bileklik, saat gibi nesnelerin üzerinde de ekran bulunacağını belirtmektedir. Bunun yanı sıra Samsung otomobillerin penceresinin, cam üzerine yansıtılmış ekrana dokunarak açılıp kapanacağını, aracın klimasının da bu ekran üzerinden ayarlanacağını, saat ve daha birçok şeyin otomobil camı üzerine yansıyan ekrandan görüntüleneceğini tahmin etmektedir. Okulda sabit panolar yerine hareketli ekran panoları olacaktır. Ayrıca okullarda öğrencilerin (farklı sınıflarda olsa da) aynı üç boyutlu şekil üzerinde birbirlerini cam ekranlar sayesinde görerek oyun oynayabilecekleri düşünülmektedir. Saydam asansörler üzerinde de ekranlar olacağı beklentiler arasındadır (https://www.youtube.com/watch?v=XyIvSIY0MTM, 31/05/2015 tarihinde indirilmiştir.). 
IBM (International Business Machines)'e göre ise, yakın gelecekte bilgisayarlar da insanlar gibi dokunma, görme, tatma, duyma ve koklama duyularına sahip olacaktır.

- Dokunma: Telefonu kullanarak cisim ve nesnelere dokunma hissi olabilecektir.

- Görme: Bilgisayarlar her şeyi görerek tanıyacaktır.

- Duyma: Bilgisayarlar önemli olan şeyleri duyacaktır.

- Tatma: Bilgisayarlarda dijital tat alıcılar bulunacaktır.

- Koklama: Koku alma hissine sahip bilgisayarlar üretilecektir (http://money.cnn.com/gallery/technology/innovation, 17/05/2015 tarihinde indirilmiştir.).

Microsoft'a göre ise gelecekte yabancı bir ülkeye seyahat edildiğinde reklam panolarında veya başka yerlerde yazılı olan yabancı dildeki yazılar takılan bir gözlük sayesinde istenilen dile çevrilebilecektir. Daha da ötesi araba ile yolculuk ederken ertesi gün kişinin bir programının ya da toplantısının olduğu bir binanın yakınından geçilirse o binanın yanında, görülebilecek bir şekilde kişinin randevusunun orada olduğu yazacaktır. Eğer bir otelde kalınacaksa yolculuk esnasında odanın hazır olduğu telefon ekranından görüntülenecektir. Konukların bagajlarını odalarına taşıyan otel görevlisinin kart ekranına otele kaç kişi geleceği, kaç çantasının olduğu, çantalarının ağırlıklarının ne kadar olduğu, müşterinin ne zaman geleceği gibi bilgiler yansıyacaktır. Ayrica Microsoft gelecekte reklam veya konser tanıtımlarının da ekran üzerinden yapılacağını; fakat bu tanıtımların hareketli olacağını tahmin etmektedir. Örneğin bir yerdeki tanıtımda görülen hayır konserine yardımda bulunmak için ekranda görülen tanıtım sadece cep telefonundan çekilerek istenilen miktarın bağışlanabileceği düşünülmektedir. İş yerlerinde ince, geniş ekranlar kullanılabilecektir. Kişiler evlerinden, yakınlarından uzakta olsalar da ekranlar sayesinde evlerinde yapılacak işleri kontrol altında tutabilecektir. Öğrenciler ödevlerini veya derslerini ekranlar üzerinden yapabilecek, yapılanların doğruluğu veya yanlışlığı anında kontrol edilebilecektir (https://www.youtube.com/watch?v=d8MlXw0zk64，30/05/2015 tarihinde indirilmiştir.).

Microsoft'un bir başka gelecek senaryosuna göre cep telefonları incelecek ve çerçeveleri olmayacaktır. İstenildiğinde iki parçaya ayrılabilecek ve parçaların biri ahize olarak kulağa götürülürken diğeri aranılan kişileri canlı olarak görmeyi ve konuşmaları farklı bir dilde ise istenilen dile çevrilmesini sağlayacaktır. Ayrıca cep telefonları, ekranının yürüdüğümüz yol üzerine yansıması sonucu oklar yardımıyla yol gösterici 
olarak da kullanılabilecektir. İnsanların taşıdıkları küçük ekranların kaydırma hareketi ile kablosuz, araçsız bir şekilde duvarda bulunan ekranlara yansıyabileceği, küçük bir anahtarlık içinde bulunan bilgilerin parmak iziyle alınan şifre sonucu masa üzerinde görüntülenebileceği düşünceler arasındadır. Hatta uçak biletlerinin üzerinde bile ekranların bulunacağ1 tahmin edilmektedir. Daha da ötesi gelecekte çay, kahve vb. içilen bardaklar üzerinde de ekranların bulunacağı ve içeceğin sıcaklığının anlık olarak ölçebileceği beklenmektedir. Microsoft'a göre ilerleyen yıllarda öğrenciler iki farklı sınıfta, hatta farklı ülkede olsa da birbirleriyle ekranlar aracılığıyla yüz yüze görüşebilecek, farklı dillerdeki konuşmaları ekran üzerinden çevrilebilecektir. Ekrana her iki sınıftaki öğrenci kalemsiz olarak parmakları ile resim çizebilecektir. Aynı anda iki ayrı ülkedeki sınıfta aynı ders işlenip görseller üç boyutlu hâle gelebilecektir. Farklı yerlerde olsa da veliler ekranları üzerinden çocuklarının neler yaptığını görüp izleyebilecektir. Ekranlar camlar üzerine yansıyıp iş ve işlemler dokunma yoluyla camlar üzerinden gerçekleşecektir. Fare istenildiğinde masa üzerine yani ekrana yansiyabilecektir. Microsoft gelecekte gazetelerin e-ink teknolojisiyle esnek, elektronik kâğıtlara yazılacağını; böylece günümüzdeki gazeteler gibi eğilip bükülebileceğini; fakat şimdiki gazetelerden oldukça farklı tasarlanacağını tahmin etmektedir. Gazetelerin görsellerinin hareketli olması, her haber yazısının tıpkı tabletlerde gazete okur gibi kaydırma hareketi ile kontrol edilmesi ve okunmak istenilen yazının başlığ 1 gazete üzerinde dokunma yoluyla tıklanarak açılması gelecek beklentileri arasindadir(https://www.youtube.com/watch?v=aJu6GvA7jN8， 18/05/2015 tarihinde indirilmiştir.).

\section{Sonuç ve Tartışma}

Intel, Samsung, IBM, Microsoft gibi önde gelen şirketlerin gelecekte ekranlar hakkında çok sayıda tahminleri vardır. Intel insanların ekranlara konuşma komutları verilebileceğini, cep telefonu, bilgisayar ve kol saatlerinin paralel çalışabileceğini vurgularken; Samsung kıvrılabilir, katlanabilir ve kırılmaz OLED ekranların otomobillerde, okullarda, iş yerlerinde olacağını belirtmiştir. IBM ise ileride bilgisayarların beş duyu organına sahip olacağını ve buna bağlı olarak her alanda kullanılabileceğini düşünmektedir. Microsoft da bilgisayarların küçüleceği, ekranlar yoluyla bir dilden başka bir dile çeviri yapılabileceği, ekranların her zaman, her alanda kullanılacağı, hareketli gazete ekranlarının olacağı vb. gibi birçok tahminde bulunmaktadır. Aslında, yapılan çıkarımlar sonucunda incelenen lider bilişim teknolojisi firmalarının hepsi de gelecekte ekranların yaşamın her 
noktasında olacağını açıklamaya çalışmaktadır. $\mathrm{Bu}$ da ekran okuryazarlığının gelişmek zorunda olduğunun en büyük göstergesidir.

Gelecekte teknoloji o kadar ön plânda olacak ki teknolojiden yoksun veya uzak bir kişi çağ dışı olarak görülecek. Teknoloji belki de aklın önüne geçecektir. "Gelecekte, akıllı olsa da dijital bilgiye sahip olmayan bir insan, akılsız ama dijital bilgiye sahip olan bir insanın edindiği bilgelik araçlarına erişemeyebilir"' (Prenksky, 2009).

İlerleyen yıllarda bilgisayarın gelişiminin daha da hızlı olması beklenmektedir. Ayrıca geliştirilecek olan bilgisayarların kararlarını kendisinin vermesi, yeni düşünceler geliştirmesi bilgisayarlarla ilgili gelecek senaryolarından bazılarıdır. İlk bilgisayarlar çok büyükken, şu anda bireyler her yerde, her durumda işlerini yönetmek için kolayca taşınabilen cep telefonları ve tabletleri bir bilgisayar gibi kullanabilmektedir. Bu durum göz önüne alınırsa gelecekte bilgisayarların daha da küçülmesi şaşırtıcı olmayacaktır. Bu sebeple gelecekte teknolojik araçların ağırlık ve hacminin neredeyse yok olacağı, bilgisayarların yerine küçük aparatların taşınacağı beklentiler arasındadır. Bu aparatlar sayesinde bilgiler, görseller, videolar vb. masa, pencere, ayna gibi düz zeminler üzerine yansiyacaktır. Hatta sadece bilgisayarın monitörü değil bunun yanında klavyesi de düz zemine yansıyacak ve şimdiki gibi klavyeden de işler yönetilip, yazılar yazılabilecektir.

İlerleyen yıllarda teknoloji mağazalarından bilgisayar satın almak istenildiğinde içinde şifre bulunan küçük bir zarf verilecektir. Her yerde kolayca bulunabilecek olan bilgisayar düğmelerine basıp şifre girildiğinde kişiye ait bilgisayar ekranı açılmış olacaktır. Bu sayede kişiler şu anda olduğu gibi bilgisayarlarını yanlarında taşımak için büyük çantalar kullanmak zorunda kalmayacaktır.

Gelecekte ilköğretimin ilk günlerinden itibaren okul çantalarının içinde kitap, defter, silgi gibi araç-gereçlerin olacağı düşünülmemektedir. Öğrencilerin kalemleri bulunacak fakat şu andaki gibi kurşun kalem, renkli kalem, vb. yerine istenildiğinde kurşun kalem, istenildiğinde tükenmez kalem, dolma kalem ya da boya kalem hissini veren kalemler olacaktır. Öğrenciler okuma yazmayı da defterler üzerinde değil ekran üzerinde yazarak öğrenecektir. Tonta (2009: 748) dijital yönden güçlendirilmiş insanı "dijital insan" olarak adlandırmaktadır. Gelecekteki öğrenciler ise Prensky'e (2001) göre "dijital yerliler"dir. Onlar günümüzdeki pek çok insan gibi teknolojiyle sonradan tanışmayıp, var oldukları andan itibaren teknoloji hayatlarında yer edinmiş olacaktır. Bu sebeple de okullarda ekran okuryazarlığ gelişmiş olup, eğitim de ekranlar üzerinden yapılabilecektir. 
Bilgisayar destekli öğretim ile okuma öğrencilerin okuma potansiyellerinin gelişmesinde öğretmenlere yardımcı olmak için güçlü bir eğitim aracı olarak hizmet verebilecektir (Soe vd., 2000: 21).

Gelecekte her öğrenci sırası ya da masası üzerinde küçük bir düğme bulunacaktır. Öğrenciler bu düğmelerin üzerine basıp şifrelerini girecekler ve bu sayede "kitap dolu ağır çantaları taşımak yerine" (Poftak, 2001: 22) eğitim faaliyetlerini sürdürebilecekleri bilgisayar ekranları açılmış olacaktır. Bu ekranlar bazen bir duvar, bazen bir masa, bazen de bir cam üzerine yansıyacaktır. Hatta bu görüntüler sadece iki boyutlu değil istenildiğinde üç boyutlu hâle de gelebilecektir. Şu anda sınıflardaki materyalleri taşıma ve saklama sıkıntısı yaşanmaktadır. Hatta birçok köy okulu için materyal edinme problemi vardır. Fakat üç boyutlu ekranlar sayesinde hiçbir materyali taşıma, saklama ve edinme sorunu yaşanmayacaktır. Söylenenler, gerçekleşmesi çok uzak durumlar gibi görünse de; aslında bu teknolojilerle karşılaşmamız olanaksız değildir.

Bozkurt ve Bozkaya'ya (2013: 8) göre, gelecekte etkileşimli ekitapların hareketi tanıyan bir arayüze sahip olması beklenmektedir. Ayrıca e-kitapların gelecekte yaşamda daha fazla yer alması düşünülmektedir. Buna bağlı olarak günümüzde olduğu gibi hem dijital kütüphaneler olacak hem de basılı yayınlardan oluşan kütüphaneler bulunacaktır. Yani kütüphaneler sadece fiziksel mekânlar değil, mobil bilgi hizmetleri sunan sanal ortamlar (Murray, 2006) olacaktır. Dolayısıyla gelecekte de bu sanal ortamlar etkin kullanılırken, basılı yayınlardan oluşan kütüphaneler bir müze gibi sadece eski yıllara ait kitapların bulunduğu mekânlar haline gelecektir. O'Hara ve Sellen (1997: 342) kâğıtsız bir gelecek beklenebileceğini vurgulamaktadır. Çünkü e-kitaplar basılı kitabın yerini alacağı için basılı materyaller git gide azalacaktır. Bu duruma göre gelecekte kitapları somut olarak ele alıp okumanın tadı unutulacaktır fakat; kim bilir belki de bundan 30 yıl sonra insanlar kitaplarını yataklarında küçücük bir aparat sayesinde üç boyutlu olarak okumanın tadını çıkarıyor olacaktır.

Bundan birkaç yıl öncesine göz atıldığında, ekran okuryazarlığının ne kadar geliştiğini ve gelecekte de bu gelişimden kaçmanın imkânsız olacağını görmek herkes için çok zor değildir. Evde, okulda, işte, yolculukta hayatın her noktasında ekranlarla içi içe olunacaktır. En çok da bilginin üretildiği ve aktarıldığı alan olan eğitimde ekranlardan uzak durmak neredeyse olanaksız bir durum hâline gelecektir. Bu nedenle ekran okuryazarlığı alanında çalışmaların artırılması gerekmektedir.

Fatih Projesiyle her öğrenciye ve öğretmene tablet dağıtma fikri de ekran okuryazarlığının geliştirilmesi gerektiğinin göstergesidir. Bu sebeple öğretmenlerimiz ve öğrencilerimiz ekran okuryazarlığı becerilerini 
geliştirerek yollarına devam etmelidirler. Gelecek bilgi teknolojilerine ayak uyduramayan eğitimcilerin başarılı olmaları imkânsızlaşacaktır.

\section{Kaynakça}

Aydoğan, D. (2014). Romanda Dijitalleşme: E-kitap. The Turkish Online Journal of Design, Art and Communication, 4 (4), 16-32.

Bozkurt, A. ve Bozkaya, M., (2013). Etkileşimli E-kitap: Dünü, Bugünü, Yarını. Akademik Bilişim, Antalya: Akdeniz Üniversitesi. 1-11.

Büyüköztürk, Ş., Kılıç-Çakmak, E., Akgün, Ö. E., Karadeniz, Ş. ve Demirel, F. (2014). Bilimsel Araştırma Yöntemleri, Ankara: PegemA Akademi.

Çetin, Ö., Çakıroğlu, M., Bayılmış C. ve Ekiz H. (2004). Teknolojik Gelişme İçin Eğitimin Önemi Ve İnternet Destekli Öğretimin Eğitimdeki Yeri. The Turkish Online Journal Of Educational Technology - TOJET, 3 (3), 144-147.

Day, R. (2001). Reading The Future. Popular Mehanics, 178 (4), 82-85.

Dillon, A. (1992). Reading From Paper Versus Screens: A Critical Review Of The Empirical Literature. Ergonomics, 35 (10), 1297-1326.

Ertem, İ. S. ve Özen, M. (2014). Metinleri Ekrandan Okumanın Anlam Kurma Üzerine Etkisi. The Journal Of Academic Social Science Studies International Journal Of Social Science Doinumber:http://dx.doi.org/10.9761/JASSS2161, 24, 319-350.

Grace, K. E. (2011). Comparing The İpad To Paper: Increasing Reading Comprehension in Digital Age. Unpublished Master's Thesis, Graduate College of Bowling Green State University, USA.

Greenlee-Moore, M. E. \& Smith, L. L. (1996). Interactive Computer Software: The Effects On Young Children's Reading Achievement. Reading Psychology, 17 (1), 43-64.

Grimshaw (2007). Electronic Books: Children's Reading and Comprehension. British Journal Of EducationalTechnology, 38(4). 583-599.

Hamzaçebi, C.ve Çetiner, E. (2007). Bilgisayara Giriş, İstanbul: Beta Basım.

Hawkins, D. T. (2000). Electronic Books: A Major Publishing Revolution. Online, 24 (4), 14-25.

Herring, M. Y. (2001). Why The Internet Can't Replace The Library. Education Digest, 67 (1). 46-49.

Hull G. A., Mikulecky, L., Clair, R. \& Kerka: (2003). Multiple Literacies. A Compilation For Adult Educators. Center on Education and Training For Employment, Colombus OH. 
İspir, B., Birsen, H.,Binark, F. M., Özata, F. Z., Bayraktutan, G., Öztürk, M. C., Yılmaz, R. A. ve Ayman, M.(2013). Dijital İletişim Ve Yeni Medya, Eskişehir: Web-Ofset.

Kaya, M. T., Kılıçoğlu, O., Yanarateş, E., Karacı, A., Özdemir, Y., Özdemir, İ., Başboğaoğlu, U. ve Kara M. (2005). Bilgisayara Giriş, İstanbul: Lisans Yayıncilık.

Khan, M. \& Raza, M. (2012). Suitable Lenght Of Text On The Bases Of Eye Blink For Reducing Maximum Focus Loses. International Journal of Computer Applications, 37(8), 15-21.

Kurudayığlu, M. ve Tüzel: (2010). 21. Yüzyıl Okuryazarlık Türleri, Değişen Metin Algısı Ve Türkçe Eğitimi. TÜBAR-XXVIII, 283-298.

Leu, D. J. (2006). New Literacies, Reading Research, And The Challenges Of Change: A Deictic Perspective. The 55th Yearbook Of The National Reading Conference, 1-20.

Maden: (2012). Ekran Okuma Türleri Ve Türkçe Öğretmeni Adaylarının Ekran Okumaya Yönelik Görüşleri. Dil ve Edebiyat Eğitimi Dergisi, 1 (3), 1-16.

Murray, R. (2006). Library Systems: Synthesise, Specialise, Mobilise. Ariadne, No. 48.

O'Hara, K. \& Sellen, A. (1997). A Comparison of Reading Paperand On-Line Documents. CHI 97 Electronic Publications: Papers, 335-342.

Özçatalbaş, O., Döğerlioğlu, G. ve Özmen, H. (2008). Fakülteler Ve Yüksekokullar İçin Bilgisayar, İstanbul: Ekin Basım Yayın Dağıtım.

Pala, Z. (2008). Yeni Başlayanlar İçin Bilgisayar, İstanbul: Türkmen Kitabevi.

Poftak, A. (2001). Getting A Read on E-Books. Technology \& Learning, 21 (9), 22-30.

Prensky, M. (2001). Digital Natives, Digital Immigrants. NCB University Press, 9 (5).

Prensky, M. (2009). H. Sapiens Digital: From Digital Immigrants And Digital Natives To Digital Wisdom. Innovate: Journal Of Online Education, 5 (3).

Rockinson-Szapkiw, A. J., Courduff, J., Carter, K. \& Bennett D. (2012). Electronic Versus Traditional Print Textbooks: A Comparison Study On The İnfluence Of University Students' Learning. Computers $\mathcal{E}$ Education, 63. 259-266.

Sayer C. R. (2007). “Çocuk Kütüphanelerinde Elektronik Yayınların Kullanımı Ve Yaygınlaştırılması", Yüksek Lisans Tezi, Ankara Üniversitesi Sosyal Bilimler Enstitüsü, Ankara. 
Schoeller, B. (2005). The Effects of Reading Goals On Learning İn A Computer Mediated Environments. Journal of Issues in Informing Science And Information Technology, 2, 405-422.

Sert, G., Kurtoğlu, M., Akıncl, A. ve Seferoğlu: S. (2012). Öğretmenlerin Teknoloji Kullanma Durumlarını İnceleyen Araştırmalara Bir Bakış: Bir İçerik Analizi Çalışması. Akademik Bilişim, 1-8.

Soe, K., Koki: \& Chang, J. M. (2000). Effect Of Computer-Assisted Instruction (CAI) On Reading Achievement: A Meta-Analysis, Washington: Pacific Resourcesfor Education And Learning Institution.

Tonta, Y. (2009). Dijital Yerliler, Sosyal Ağlar ve Kütüphanelerin Geleceği. Türk Kütüphaneciliği, 23 (4), 742-768.

Internet Kaynakçası

http://www.tdk.gov.tr. Büyük Türkçe Sözlük.

http://tr.wikipedia.org.

http://www.theguardian.com/ebookstechnology. Ebook Timeline.

http://mebk12.meb.gov.tr. Bilgi Teknolojisinin Temel Kavramları.

https://www.youtube.com.

http://money.cnn.com 